\title{
Long-Time Stability of Ni-Ti-Shape Memory Alloys for Automotive Safety Systems
}

\author{
Joachim Strittmatter and Paul Gümpel
}

\author{
(Submitted May 10, 2010; in revised form October 13, 2010)
}

\begin{abstract}
In automotive a lot of electromagnetically, pyrotechnically or mechanically driven actuators are integrated to run comfort systems and to control safety systems in modern passenger cars. Using shape memory alloys (SMA) the existing systems could be simplified, performing the same function through new mechanisms with reduced size, weight, and costs. A drawback for the use of SMA in safety systems is the lack of materials knowledge concerning the durability of the switching function (long-time stability of the shape memory effect). Pedestrian safety systems play a significant role to reduce injuries and fatal casualties caused by accidents. One automotive safety system for pedestrian protection is the bonnet lifting system. Based on such an application, this article gives an introduction to existing bonnet lifting systems for pedestrian protection, describes the use of quick changing shape memory actuators and the results of the study concerning the long-time stability of the tested NiTi-wires. These wires were trained, exposed up to 4 years at elevated temperatures (up to $140{ }^{\circ} \mathrm{C}$ ) and tested regarding their phase change temperatures, times, and strokes. For example, it was found that $A_{\mathrm{P}}$-temperature is shifted toward higher temperatures with longer exposing periods and higher temperatures. However, in the functional testing plant a delay in the switching time could not be detected. This article gives some answers concerning the long-time stability of NiTi-wires that were missing till now. With this knowledge, the number of future automotive applications using SMA can be increased. It can be concluded, that the use of quick changing shape memory actuators in safety systems could simplify the mechanism, reduce maintenance and manufacturing costs and should be insertable also for other automotive applications.
\end{abstract}

Keywords functional materials, pedestrian safety system, quick changing actuator, shape memory alloys, smart materials

\section{Introduction}

Recently, the number of safety systems in modern cars has been increased steadily and thereby caused a reduction of injured or killed car passengers worldwide, in spite of the fact that the total car number increased from year to year (Ref 1-3). In contradiction to the elevated security for car passengers the number of pedestrians that were slightly, severely or fatally injured during car accidents is still very high (Ref 4). One effective automotive safety system for pedestrian protection is the bonnet lifting system (Ref 5). In the past years different

This article is an invited paper selected from presentations at Shape Memory and Superelastic Technologies 2010, held May 16-20, 2010, in Pacific Grove, California, and has been expanded from the original presentation.

Joachim Strittmatter and Paul Gümpel, WITg Institut für Werkstoffsystemtechnik Thurgau an der Hochschule Konstanz, CH-8274 Tägerwilen, Switzerland; and HTWG KONSTANZ University of Applied Sciences, D-78462 Constance, Germany. Contact e-mails: joker1@htwg-konstanz.de, j.strittmatter@witg.ch, guempel@htwgkonstanz.de, URL: www.witg.ch and URL: www.htwg-konstanz.de. researchers have presented such systems (Ref 6-8) that generally are able to lift the bonnet during a crash with a pedestrian in order to absorb a part of impact energy when the pedestrian crashes into the bonnet and thereby reduce pedestrian's injuries. Besides the abovementioned systems that are not yet ready to market, some systems have been used in a series of cars, such as Honda Legend (Ref 9), Jaguar XK (Ref 10), Citroën C6 (Ref 11), and Mercedes E-class (Ref 12).

However, for the lifting of the bonnet, fast actuators are necessary because there is only a very short reaction time - about less than $60 \mathrm{~ms}$ - from the initial touch of the pedestrian with the bumper to the crash of him into the bonnet. In nearly all of these existing systems the actuator operations are irreversible and the whole system has to be reset in the garage.

\section{Describing of the Existing Bonnet Lifting System}

Our research group started in 2001 to develop quick changing shape memory actuators in a phase, when the existing sensors in the bumper were not reliable enough to distinguish, whether a pedestrian's leg, a ball, a bird or something else was touched and therefore had the disadvantage of being very cost intensive because the pedestrian safety system has to be renewed after every faulty activation. Therefore, our idea is to replace the used electrical, pneumatic, or hydraulic actuators by reversible shape memory actuators. The function of this system 
was already described in Ref 13 . The requirements for the shape memory actuator were specified as follows (Ref 14):

- Operating temperature: -40 to $+125{ }^{\circ} \mathrm{C}$

- Actuating time: $<35 \mathrm{~ms}$

- Actuation force (using a ratio): 200-300 N

- Long-time stability of the used materials

\section{Shape Memory Alloys and Their Potential in Automotive Industry}

Shape memory materials show the particular capacity to revert to their original form when heating if they are plastically deformed below a critical temperature before (Ref 15). This effect is the result of a solid state phase change of these special alloys. For detailed information on SMAs and the SME, see Ref 16. In general, the SME involves a considerable reset force and therefore facilitates their application as actuators. Therefore, it is possible to create a spontaneous contraction of a metallic element in the range of some percent through heating. Such actuator applications can be found, e.g., as adjusting, combining, supporting or contacting elements, as active implants or as high-damping spring elements. They also find applications as sensors and actuators in passenger cars.

In a modern passenger cars there are several electromagnetic actuators for different functions, including comfort systems for the driver and passengers, actuators for engine control or vehicle control, servo-microactuators for power systems and aerodynamics. New approaches based on smart materials, instead of the traditional electromagnetic motors, can simplify the actuation in most cases, performing the same function with reduced size, weight and cost, optimizing the movement and also offering the opportunity to implement new functions (Ref 15). They also offer additional advantages, e.g., smooth direct movement with high torque or force, no additional mechanism, noiseless operation and intrinsic reliability, since the motion is related to the physical properties of the material. Therefore, the most interesting actuation functions are those in components used occasionally with nonrotary movements, such as rear-view mirror folding, movement of the climate control flaps for air flow adjustment and lock-latch controls (Ref 17). Some general potential vehicle applications for shape memory materials are shown in Fig. 1.

In modern automotive engineering, especially the use of quick changing actuators in applications concerning safety regulations is continuously increasing. By using intelligent materials, e.g., SMA, an actuator function can be realized easily. In addition, in comparison with systems driven by pyrotechnic ignition devices, with such systems it is possible to carry out the actuator function repeatedly. The use of shape memory materials in such safety systems is reduced because of the lack of material knowledge on this section. A central problem is the durability of the switching function which still has to be proved.

\section{Quick Changing Shape Memory Alloys}

An easily and quickly working actuator principle based on NiTi-wires for a future use in a bonnet lifting system for pedestrian protection was developed in different steps (Ref 18, 19). In these works it has been proved that SMA are suitable to fulfill the requested actuating times and forces for this application. In various test series, $\mathrm{Ni}-\mathrm{Ti}$ wires were tested to achieve the short contraction times and to lift the corresponding mass of a bonnet of $20 \mathrm{~kg}$. The activation of the shape memory elements was realized by electrical discharge of a capacitor system. Best results were achieved using a configuration with $30 \mathrm{Ni}$-Ti wires that were plaited to a so-called shape memory muscle. This configuration was actuated via electrical discharge of a capacitor and was able to lift a weight of $20 \mathrm{~kg}$ (bonnet) over a lifting distance (stroke) of $12.5 \mathrm{~mm}$ within less than $35 \mathrm{~ms}$ (Ref 18).

\section{Aging of the Wires}

The long-time stability of the shape memory actuators is a significant point that has to be assured. Safety systems in general could be activated within the first days of a car's lifetime or after several years, but the functionality of the whole system and especially the actuators should be reliable at any time. In practice, the long-time stability can be proved through a testing method on exposed specimens. By exposing the shape memory specimens a so-called aging process occurs and a statement concerning the functionality of the specimens can be made. The test procedure bases on the well-known fact that the parameters time and temperature have a direct interrelationship. Hence, it is possible to achieve artificial aging when the factor time is replaced through the factor temperature in a certain range. In the case of SMA, this interrelation cannot completely

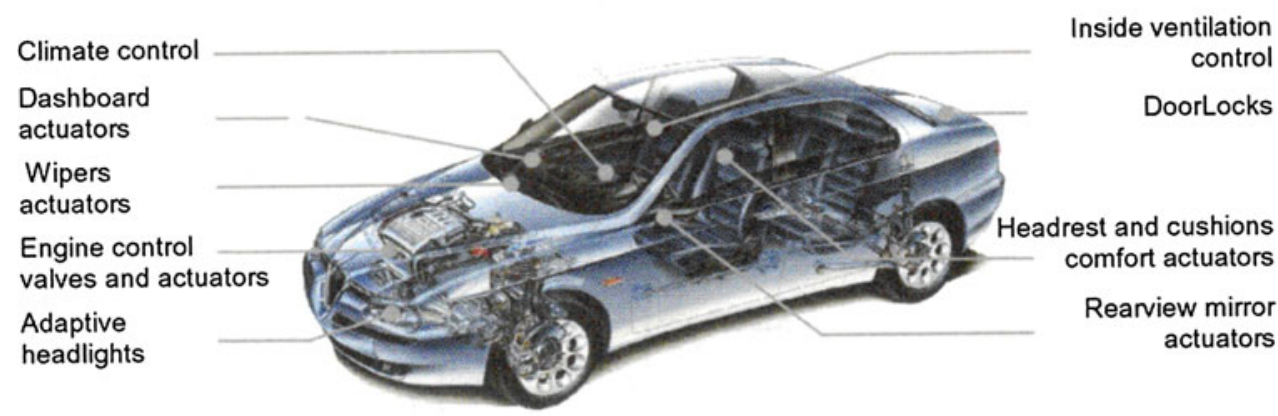

Fig. 1 Potential vehicle applications for shape memory components (Ref 15) 
be used because no phase change should occur during aging. In this investigation, binary Ni-Ti wires from Memory-Metalle $\mathrm{GmbH}$ were used with the following specifications: NiTi hightemperature actuator alloy Dy90 with $54.4 \mathrm{wt} \% \mathrm{Ni}$, diameter $0.254 \mathrm{~mm}$, annealed, oxidized and thermomechanically stabilized, $A_{\mathrm{P}} 98^{\circ} \mathrm{C}$.

To assure at every temperature that the prestrained wires still have martensitic structure, according to the requirements for parts in the engine compartment, the aging temperatures are chosen between 60 and $140{ }^{\circ} \mathrm{C}$. In checking tests it was certificated with increased weights that even at $140{ }^{\circ} \mathrm{C}$ the prestrained wires were still martensitic in the fixing device. For example, the $A_{\mathrm{F}}$ temperature of wires charged with an additional weight of $1.981 \mathrm{~kg}$ (that corresponds to a tension in the wires of $450 \mathrm{~N} / \mathrm{mm}^{2}$ ), was shifted to $160{ }^{\circ} \mathrm{C}$. And checking tests with additional weights of $2.610 \mathrm{~kg}(=550 \mathrm{~N} /$ $\mathrm{mm}^{2}$ ) showed no contraction at all even when heated up to $200{ }^{\circ} \mathrm{C}$. As the prestrained wires were fixed in very rigid fixing devices it can be assured, that they were still martensitic during the exposure times, even at $140{ }^{\circ} \mathrm{C}$. For each test step concerning aging temperature and exposure time six specimens were aged over different periods of time up to 1560 days. Figure 2 shows an overview of the temperature groups and exposure time in the aging matrix.

According to the experiences in aging tests of metallic material without SME, possible aging effects are expected after a short time in the high-temperature groups and in a longer time in the lower temperature groups, respectively. Therefore, the removal of specimens aged at 140 and $120{ }^{\circ} \mathrm{C}$ started already some days after the beginning of the aging, while the specimens aged at lower temperatures were planned to be removed at a later date. At the beginning of the aging procedure more wires were exposed in the aging furnaces, so that it was also possible to realize the tests not only of the specimens that correspond to the colored boxes in Fig. 2, but also of the dotted boxes that are displayed in the lower area of the temperature groups. It also has to be noticed that there is a big gap between the removal after 180 and 1560 days. This fact was not planned at the beginning of the aging process, but results from the test data and the idea to realize the longest possible exposure time with the last batch of specimens.

\section{Test Facilities}

In two special developed testing facilities these specimens were further examined. In the first one, the oil bath testing facility, up to six specimens of the shape memory wires can be examined under constant tension of $135 \mathrm{~N} / \mathrm{mm}^{2}$ while heating and cooling the oil bath between 10 and $170{ }^{\circ} \mathrm{C}$ in order to determine the contraction value and the characteristic points of the phase change temperature. With this data even the smallest behavior differences can be analyzed in the specimens. By comparing the data of the exposed specimens with the reference wires (kept at room temperature), possible aging effects on the shape memory effect can be noticed immediately. In the second one, the quick changing testing facility, possible influences of aging on the shape memory effect of actuator wires concerning their functionality can be investigated (Ref 19). In this testing facility a single wire specimen is connected on one side to a fixed mounting and on the other side to a mobile weight over a pulley to apply the constant tension of $135 \mathrm{~N} / \mathrm{mm}^{2}$. The specimen will be quickly activated by an electrical discharge of a capacitor system with a very high-electrical power density. For schematic views and detailed description of these facilities see Ref 13, 19.

\section{Results}

According to the aging matrix in Fig. 2 three wires of every temperature group and exposure time were tested in the oil bath test. Then for each temperature group an "overall diagram" that we call "global map" was prepared where possible shifting of the $A_{\mathrm{P}}$-temperatures can be seen as trend lines over the exposing time till 1560 days. In every temperature group, the $A_{\mathrm{P}}$-temperature of the first test is shifted to higher values in comparison to the

\begin{tabular}{|c|c|c|c|c|c|c|c|c|c|c|c|c|c|c|c|}
\hline Temp. & \multicolumn{3}{|c|}{$140^{\circ} \mathrm{C}$} & \multicolumn{3}{|c|}{$120^{\circ} \mathrm{C}$} & \multicolumn{3}{|c|}{$100^{\circ} \mathrm{C}$} & \multicolumn{3}{|c|}{$80^{\circ} \mathrm{C}$} & \multicolumn{3}{|c|}{$60^{\circ} \mathrm{C}$} \\
\hline Days & 1. Test & 2. Test & 3. Test & 1. Test & 2.Test & 3.Test & 1. Test & 2. Test & 3. Test & \begin{tabular}{|l|} 
1.Test \\
\end{tabular} & 2. Test & \begin{tabular}{|l|} 
3.Test \\
\end{tabular} & 1.Test & 2. Test & 3.Test \\
\hline 4 & & & & & & & & & & & & & & & \\
\hline 6 & & & & & & & & & & & & & & & \\
\hline 8 & & & & & & & & & & & & & & & \\
\hline 10 & & & & & & & & & & & & & & & \\
\hline 12 & & & & & & & & & & & & & & & \\
\hline 16 & & & & & & & & & & & & & & & \\
\hline 20 & & & & & & & & & & & & & & & \\
\hline 24 & & & & & & & & & & & & & & & \\
\hline 30 & & & & & & & & & & & & & & & \\
\hline 40 & & & & & & & & & & & & & & & \\
\hline 60 & & & & & & & & & & & & & & & \\
\hline 90 & & & & & & & & & & & & & & & \\
\hline 120 & & & & & & & & & & & & & & & \\
\hline 180 & & & & & & & & & & & & & & & \\
\hline 1560 & & & & & & & & & & & & & & & \\
\hline
\end{tabular}

Fig. 2 Aging matrix 


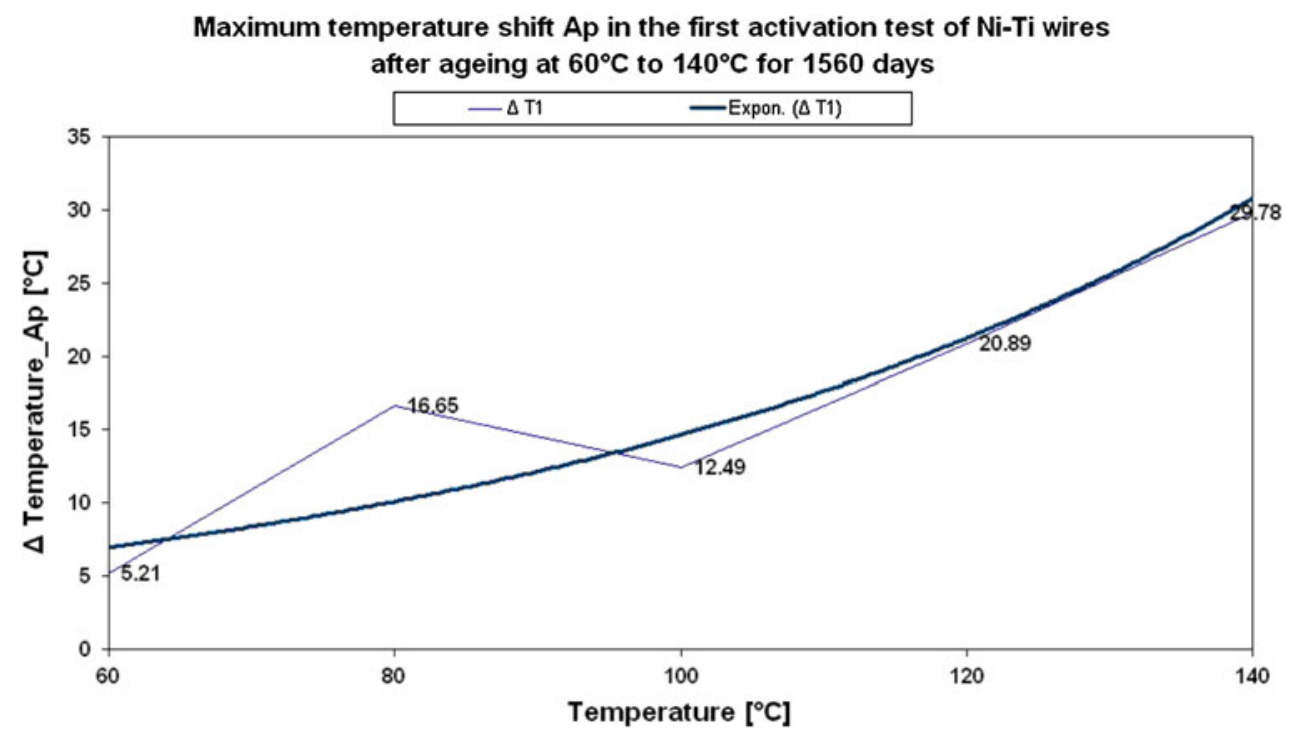

Fig. 3 Maximum temperature shift $A_{\mathrm{p}}$ in the first activation test of the NiTi-wires after aging at different temperatures for 1560 days

reference wire. The trend lines of the second and third test have the same course but their displacement concerning the reference line is much smaller. All the trend lines-even the reference line - are slightly rising with longer exposure time. It can be concluded that exposure temperature has an immediate effect on the shifting of the $A_{\mathrm{P}}$-temperature, especially in the first test after aging. The influence of the exposure time is less intensive but also leads to higher $A_{\mathrm{P}}$-temperatures.

Since the maximum shifting of the $A_{\mathrm{P}}$-temperature occurred always in the first test, special attention was given in analyzing the trend lines of the first tests. It was observed that the shifting value of the $A_{\mathrm{P}}$-temperatures is less intensive with lower aging temperature. The shifting of the $A_{\mathrm{P}}$-temperatures of the first activation tests over the aging temperature at maximum aging time is shown in Fig. 3. The displayed values were averaged over three specimens that showed a maximum variation of $1.68{ }^{\circ} \mathrm{C}$ except for specimens aged at $80{ }^{\circ} \mathrm{C}$, where the maximum variation reached $13.66{ }^{\circ} \mathrm{C}$.

In the functional tests two aged specimens from each temperature-time group was tested in the quick changing testing plant and the average graph was compared to the reference graph. In all the test data of the different temperaturetime groups no significant difference to the reference specimens could be observed. By means of a closer analyze of the stroketime diagrams of all the specimens aged at $140{ }^{\circ} \mathrm{C}$ for aging times ranging from 4 to 1560 days the maximum variation of the contraction time to reach a stroke of $6 \mathrm{~mm}$ was less than $3 \mathrm{~ms}$. Furthermore no systematic distribution of the results was found (Ref 19). It can be stated that these small differences were not caused in the material by aging differences, but in the accuracy of measurement and that no measurable influence of the aging conditions of the wires concerning their actuator function could be detected.

\section{Metallographical Investigation and Model of Aging Mechanism}

By means of structural investigations in the transmission electron microscope and microhardness measurements at

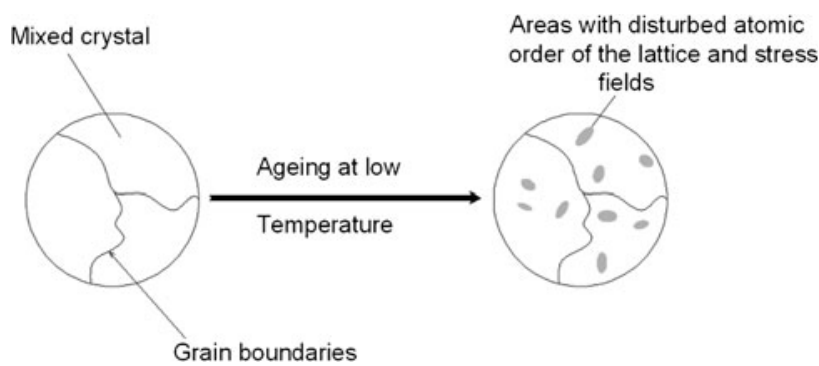

Fig. 4 Model of the aging mechanism for aging of Ni-Ti wires at temperatures up to $140{ }^{\circ} \mathrm{C}$

different exposed material no differences could be detected. It can be concluded that during aging of Ni-Ti material in this low-temperature range no serious structural change occurs in the form of precipitation building. According to the process of elimination and our metallographical experience the aging mechanism turns out to be a phenomenon of several components. As a reason for these slight structural changes that occured during aging in this low-temperature range and that were detected in the results of the specimens tested in the oil bath testing plant, modifications in the homogeneity of the atomic order of the lattice are considered (see Fig. 4). These modifications can be caused by

- diffusion processes,

- segregation of atoms as a preliminary stage of precipitation processes (especially thermal activated) and/or,

- changes of the vacancy distribution.

\section{Conclusions}

Concerning the present results it can be concluded:

(1) Pedestrian safety systems play an increasing significant role to reduce injuries and fatal casualties caused by 
accidents. The practice proved that the bonnet lifting system is an effective automotive safety system for pedestrian protection which has been adopted by more and more car manufactures.

(2) The results of prototype tests proved that shape memory alloys are suitable to fulfill the requested actuating functions in the bonnet lifting system.

(3) The results of the oil bath tests proved that aging temperature and exposure time have a measurable effect on the tested shape memory wires. Higher aging temperatures lead to stronger shifting of the $A_{\mathrm{P}}$-values while the influence of longer exposure time is not so strong. The displacements have their maximum in the first tests after aging, while the second and third test lead to smaller shifting. A maximum elevation of the $A_{\mathrm{p}}$-temperature of $29.8 \mathrm{~K}$ was measured in the specimens aged at $140{ }^{\circ} \mathrm{C}$ for 1560 days.

(4) By the results of the quick changing tests it can be stated that aging temperature as well as exposure time has no measurable effect on the function of the tested shape memory wires. First these results seem to be a contrast to the results of the oil bath tests, where a slight shifting of the $A_{\mathrm{P}}$-temperatures toward higher values was observed and therefore the activation with the same constant energy logically should lead to a measurable slowing-down of the contraction time. Considering the results of both tests it can be concluded, that through the high-speed discharge of the capacitor such a high energy is applied on the shape memory wires, that even for a $A_{\mathrm{P}}$-temperatures raise of about $29.8 \mathrm{~K}$ (in the case of the aging at $140{ }^{\circ} \mathrm{C}$ for 1560 days) no measurable influence can be detected concerning the function of the actuator wires.

(5) Metallurgical investigations at different exposed material indicate that during aging of $\mathrm{Ni}-\mathrm{Ti}$ material in this low-temperature range no serious structural change occurs in the form of precipitation building. As a reason for the slight structural change, modifications in the homogeneity of the atomic order of the lattice are considered according to the metallographical process of elimination.

(6) The use of quick changing shape memory elements as actuators in safety systems should be possible not only for the bonnet lifting system, but also for other automotive applications, compared with traditional complex and irreversible operation actuators.

\section{References}

1. V.M. Nantulya et al., Equity Dimensions of Road Traffic Injuries in Low- and Middle-Income Countries, Inj. Control Saf. Promot., 2003, 10(1), p 13-20

2. A. Bener et al., Strategy to Improve Road Safety in Developing Countries, Saudi Med. J., 2003, 24(6), p 603-608

3. M. Peden et al., World Report on Road Traffic Injury Prevention, World Health Organization, Geneva, Switzerland, 2004

4. D. Mohan, Traffic Safety and Health in Indian Cities, J. Transp. Infrastruct., 2002, 9(1), p 79-92

5. R. Froeming et al., Requirement Engineering for Active Safety Pedestrian Protection Systems Based on Accident Research, Adv. Microsyst. Automot. Appl., 2006, p 79-106

6. K. Nagatomi et al., Development and Full-Scale Dummy Tests of a Pop-Up Hood System for Pedestrian Protection, Proc. of the 19th International Technical Conference, 2005, Paper number 05-0113, http://www-nrd.nhtsa.dot.gov/pdf/esv/esv19/05-0113-O.pdf

7. K.B. Lee et al., The Study on Developing Active Hood Lift System for Decreasing Pedestrian Head Injure, Innovations for Safety: Opportunities and Challenges, 2007

8. B.M. Barnes et al., Shape Memory Alloy Resetable Spring Lift for Pedestrian Protection, Proc. SPIE, 2008, 6930, p 693005.1-13

9. The Official Site of the European New Car Assessment Programme: http://www.euroncap.com/tests/honda_legend_2007/283.aspx

10. Pedestrian Deployable Bonnet System, http://www.birmingham101. com/101motors jag bonnet.htm

11. The Official Site of the European New Car Assessment Programme: Citroen C6, http://www.euroncap.com/tests/citroen_c6_2005/235.aspx

12. Neue E-Klasse mit aktiver Motorhaube, High TechReport 1/2009, http:/www.daimler.com/dccom/0-5-1217018-49-1218263-1-0-0-0-0-08-7165-0-0-0-0-0-0-0.html

13. S. Gläser et al., Long-Time Stability of Quick Changing Shape Memory Actuators, Proc. of the 10th International Congress on New Actuators, ACTUATOR 2006, Bremen, Germany, 2006, p 920-923

14. D.J. Leo et al., Vehicular Applications of Smart Material Systems, Smart Structures and Materials, 1998 SPIE Proceedings Series; 3326 Industrial and Commercial Applications of Smart Structures and Technologies, 1998, p 106-116

15. F. Butera, Shape Memory Actuators for Automotive Applications, Shape Memory Alloys, Advances in Modelling, Applications, F. Auricchio et al., Ed., International Center of Numerical Methods in Engineering CIMNE, Barcelona, Spain, 2001, p 405-426

16. P. Gümpel et al., Formgedächtnislegierungen-Einsatzmöglichkeiten in Maschinenbau, Medizintechnik und Aktuatorik, P. Gümpel, Ed., Vol. 655, Expert Verlag, Renningen, Kontakt\&Studium, 2004, 156 pages

17. F. Butera, Shape Memory Actuators, Adv. Mater. Process., 2008, 166, p $37-40$

18. J. Franke, "Schnellschaltender Aktor aus Formgedächtnislegierung," Diploma Thesis, HTWG Konstanz, University of Applied Sciences, Konstanz, 2002, 107 pages

19. J. Strittmatter et al., Long-Time Stability of Shape Memory Actuators for Pedestrian Safety System, J. Achiev. Mater. Manuf. Eng., 2009, 34(1), p 23-30 